\title{
Prenatal growth and subsequent marital status: longitudinal study
}

\author{
David I W Phillips, David J Handelsman, Johan G Eriksson, Tom Forsén, Clive Osmond, \\ David J P Barker
}

Unmarried men have higher rates of cardiovascular disease and a shorter lifespan than married men. ${ }^{1}$ The hypotheses that have been proposed to explain this are either that healthier men tend to marry or that the social support offered by marriage is protective. It is also possible that factors leading people to remain unmarried are linked with the susceptibility to cardiovascular disease. As small size at birth is associated with an increased risk of cardiovascular disease, ${ }^{2}$ we hypothesised that restriction of prenatal growth might be associated with marital status. We tested this in two long term prospective birth cohorts of men who belonged to generations in which marriage was a social norm.

\section{Methods and results}

We studied 3577 men born at the Helsinki University Central Hospital, Finland, during 1924-33. ${ }^{3}$ We linked the birth data for these men with school records of height and weight obtained at age 15 and with census information on marital status, social class, and income in 1970. The figure shows that lower birth weight was associated with a higher percentage of men who had never married (logistic regression analysis showed that the odds ratio of marrying increased by 1.42 (95\% confidence interval 1.11 to 1.81 ) per kilogram increase in birth weight). The proportion of men marrying was also predicted by length at birth, 1.13 (1.06 to 1.20) per centimetre, head circumference, 1.14 (1.05 to 1.25) per centimetre, gestational age, 1.01 (1.00 to 1.02) per week, and younger maternal age, but not ponderal index or placental weight. In multiple logistic regressions the effect of birth weight was independent of gestational age. The 259 men who had never married were $2.0 \mathrm{~cm}$ shorter, $2.4 \mathrm{~kg}$ lighter, and thinner (body mass index $18.0 v 18.4 \mathrm{~kg} / \mathrm{m}^{2}$ ) than the other men at age 15 years. They also tended to come from lower current social classes $(3.9 \%$ unmarried among higher classes compared with 10.7\% among lower classes, $\mathrm{P}<0.0001)$ and had lower income. In further regression analysis the association between birth weight and marital status remained significant, 1.35 (1.04 to 1.75) per kg, after adjustment for maternal age, height, and weight at age 15 years, and adult social class, income, and age.

These findings were confirmed in 1659 men born in east, north, and north west Hertfordshire in the United Kingdom during 1920-30. ${ }^{4}$ In 1991, when the men were aged 59 to 73 , we asked them about their marital status and occupation and measured their heights and weights. The percentage of men who had never married varied with birth weight as for the Finnish men (fig). The 132 men who had never married were $2.1 \mathrm{~cm}$ shorter, $1.1 \mathrm{~kg}$ heavier, and had a higher body mass index $\left(27.8 v 26.7 \mathrm{~kg} / \mathrm{m}^{2}\right)$ than the other men. In a regression analysis adjusting for age, social class, and body mass index a similar relation between

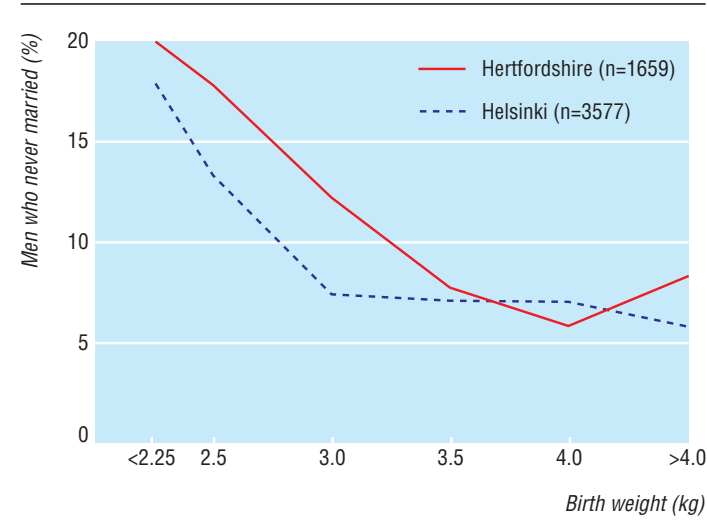

Proportion of men who had never married among those born at Helsinki Central Hospital, 1924-33, and in Hertfordshire, 1920-30

weight at birth and adult marital status emerged (odds ratio $1.51,95 \%$ confidence interval 1.08 to 2.12 ) per kilogram increase in birth weight, decreasing to 1.34 (0.94 to 1.90) after adjusting for height. In neither population were the percentage of men who reported being widowed, divorced, or separated associated with early growth.

\section{Comment}

Men who were small at birth are less likely to marry. Clearly the factors that lead men to marry are complex and include both social and biological ones. However, our data raise the possibility that early growth restriction influences the factors involved in partner selection, which may include socialisation, sexuality, personality, and emotional responses. Links between marital status and health may be established during intrauterine life.

We thank the men who participated in the Hertfordshire and Helsinki studies.

Contributors: DIWP, DJH, and DJPB wrote the paper, JGF and TF organised the data collection and commented on drafts of the paper. CO carried out the statistical analysis. DIWP will act as guarantor for the paper.

Funding: Medical Research Council and The Wellcome Trust. Competing interests: None declared.

1 Ebrahim S, Wannamethee G, McCallum A, Walker M, Shaper AG. Marital status, change in marital status, and mortality in middle-aged men. An J Epidemiol 1995;142:834-42.

2 Barker DJP. Mothers, babies and health in later life. Edinburgh: Churchill Livingstone, 1998.

3 Eriksson E, Forsén T, Tuomilehto J, Winter PD, Osmond C, Barker DJP. Catch-up growth in childhood and death from coronary heart disease: longitudinal study. BMJ 1999;318:427-31.

4 Hales CN, Barker DJP, Clark PMS, Cox LJ, Fall C, Osmond C, et al. Fetal and infant growth and impaired glucose tolerance at age 64. BMJ 1991;303:1019-22.

(Accepted 17 November 2000)
Medical Research Council

Environmental Epidemiology Unit, Southampton General Hospital, Southampton SO16 6YD David I W Phillips professor of endocrine and metabolic programming Clive Osmond reader in medical statistics David J P Barker director

National Public Health Institute, Department of Epidemiology and Health Promotion,

Diabetes and

Genetic

Epidemiology Unit, FIN-00300, Helsinki, Finland Johan G Eriksson head of unit Tom Forsén researcher

ANZAC Research Institute and Department of Andrology, Concord Hospital, Sydney, NSW 2006 , Australia David J

Handelsman

director

Correspondence to: D I W Phillips on diwp@mrc. soton.ac.uk BMJ 2001;322:771 